\title{
Does Shariah' Have an Impact on Performing Genetic Screening Test Before Marital or Pregnancy?
}

\author{
Sara Gabaren* \\ Department of nursing, West University Timisoara, Romania
}

*Corresponding author: Sara Gabaren, Department of Nursing, PhD student, West University Timisoara, Romania.
Received Date: April 01, 2020

Published Date: June 12, 2020

\begin{abstract}
Background
For the Muslim Arab population of Israel, religion has a central place in culture and daily life. As of 2018, 57\% of Israeli Arabs have defined themselves as traditional, and $31 \%$ have defined themselves as highly religious. The influence of religion is felt in areas such as employment and academic education [1]. One issue in which the influence of religion has been debated is the relationship between religion and the conduct of hereditary screenings among Muslim Arab in Israel. According to [2], on one hand the Arab women in Israel do not cite religion as a factor influencing their decision to conduct a screening test, and on the other, a significant relationship between the degree of Arab women's religiosity and the lack of responsiveness to conduct the screening test was demonstrated.
\end{abstract}

The issue of screening test among Muslim Arab women in the Mediterranean region has gained awareness in many countries. In countries such as Cyprus and the Paletstinian Authority, failure to respond to hereditary test performing can provoke a response from authorities, ranging from a substantial embezzlement to divorce up to a refusal to get a marriage lisence [3]. Also, the religious implications of the screening were discussed more than a decade ago in Saudi Arabia [4] and since then there have been no policy changes on the part of clerics in Israel.

The subject of genetic screening examinations is of particular high importance to the Arab population, as Muslim countries in the Middle East and Africa have a high prevalence of close marriages, a known risk factor for hereditary morbidity. For example, in Lebanon, up to $31.6 \%$ of marriages are among first or second cousins, whereas in the Palestinian Authority this figure reaches up to $24.2 \%$ [5].

Despite the awareness that Islam is closely linked to the various health aspects [6], the degree of clerics' awareness of hereditary screening test' significance and importance as well as their impact on conducting these tests has not been adequately studied until recently. This article will deal with preliminary research among Arab clerics in Israel on the hereditary screening examinations issue and in recent policy changes.

Keywords: Genetic test; Shariah; Hereditary diseases; Arab Muslim; Arab clerics; Awareness; Fatwa.

\section{Research Methods}

\section{Description of the sample}

This is a pilot sample of 10 participating clerics from the Arab community in Israel. This is a convenience sample. All respondents were men, married, born in the country- a very homogeneous sample.

\section{Research process}

The study was conducted at the counseling centers, religious courts and schools in the northern and central areas of Israel, among a pilot sample of 10 community-recognized clerics who were recruited into a convenience sample by handing out questionnaires to them by the researcher. After obtaining written informed consent, subjects were asked to fill out a questionnaire in Arabic on the subject of hereditary screening and demographic data. The findings of the questionnaire were analyzed by the researcher in SPSS version 24. The researcher has no personal or financial interest in the findings of the study.

\section{Research Findings}

\section{Description of the sample}

This is a pilot sample of 10 participating clerics from the Arab community in Israel. This is a convenience sample. All respondents 
were male, native, Muslim. Only 1 of the subjects was unmarried.

Table 1 shows the demographic characteristics of the study

participants.

(Table 1)

Table 1: Demographic characteristics of the sample.

\begin{tabular}{|c|c|c|}
\hline Demographic Variant & Number of Participants (N) & Percentage \% \\
\hline Marital status & 1 & 10 \\
\hline single & 9 & 90 \\
\hline married & \multicolumn{2}{|l|}{} \\
\hline Education level & 2 & 20 \\
\hline full high school diploma & 4 & 40 \\
\hline Bachelor's degree (BA) & 4 & 40 \\
\hline Master's degree (MA) & & \\
\hline
\end{tabular}

When asked about screening examinations, only one participant $(10 \%)$ replied that they did the hereditary screening, during their first partner's pregnancy. It can be seen that respondents' stated attitudes are mostly affirmative $(\mathrm{Av}=4.3-4.6)$ on the question of the dates of conducting the screening examinations, with the most positive attitude being towards the question of conducting the pre-marriage screening Table 2. In questions of attitudes toward

(Table 2)

Table 2: Summary of attitudes toward conducting genetic screening test within the sample.

\begin{tabular}{|c|c|c|c|c|}
\hline & Min & Max & Ave & Com \\
\hline Do you personally support the genetic screening test & 3 & 5 & 4.4 & 5 \\
\hline It's important to do pre-marital genetic screening test & 3 & 5 & 4.6 & 5 \\
\hline It's important to do genetical screening test before pregnancy & 3 & 5 & 4.4 & 5 \\
\hline It's important to do genetical screening test during the pregnancy & 3 & 5 & 4.3 & 5 \\
\hline Do you think it's right to condition the marriage registration on the genetical screening test & 3 & 5 & 3.5 & 5 \\
\hline Do you think there is place for legislation making the genetic screening test mandatory & 2 & 5 & 3.8 & 5 \\
\hline
\end{tabular}

\section{Discussion of Research Findings}

The attitudes of clerics in the Arab community as raised in the pilot questionnaire towards conducting genetic screening test are quite positive, with the most positive approach being towards conducting screening test even before marriage. These positive attitudes are in line with Islamic policy, which suggests that premarriage screening tests should be recommended [4]. In any case, it is of great importance to perform the tests before the 120th day of pregnancy, as it is only up to this time that an abortion can be performed in case of Identification of hereditary malformation in the fetus [7].

On the question of the attitudes of the clerics in the Arab population towards conducting the screening for the entire population, it was found that there is a significant gap between the stated positions and the conduct of the examinations in practice. While the attitudes toward conducting the screening are all neutral to positive, in fact only 2 (20\%) of the respondents conducted the screening examinations. Furthermore - while the most positive attitude was about performing pre-marital examinations, those respondents who performed the screening examinations did so already during the first pregnancy. performing genetic screening test mandatory, attitudes are less positive. It can also be seen that in the question of conditioning of the marriage on the genetic screening test the attitudes are less positive ( $A v=3.5)$. Also, in the question of legislation as a mandatory source for conducting the genetic screening test, the prevailing position is moderately positive $(\mathrm{Av}=3.8)$. positive attitudes towards conducting the screening examinations, the attitudes towards making the genetic examinations mandatory whether by law or as a condition of marriage registration are less positive. This difference is important, as clerics in the Arab community are an example, and according to Romano-Zelicha and Shochat [2], religion is indeed one of the leading causes in the Arab community for non-responsiveness to conduct screening examinations. By comparison, the policy in Cyprus is, that the church can refuse to marry a couple who has not performed hereditary examinations [3].

A possible explanation for this discrepancy between awareness and performance may be in the personal will of the respondent according to Romano Zelicha et al. [2], the absence of the obligation to conduct the examinations is a significant motive for the nonresponsiveness to the examinations' performance. In light of this approach, the World Health Organization supports the approach of making genetic screening test mandatory [8], but it can also be seen in the sample of this study that the approach toward making genetic screening test is closer to being neutral. By comparison, in Arab communities in other countries of the world, such as Gaza, 
conducting the screening test is not unequivocally mandatory, but failure to carry out the examinations is recognized by the authorities as grounds for a divorce [3].

It should be noted that this sample is a sample of males, whereas most of the research conducted on the screening is about females and it is possible that the sample consisting of female findings could be different. Also, in a broader sample of men, the findings may have been different.

\section{Presenting the Findings to a Religious Policy Manager}

About a month after the findings' analyzation was completed, the report was presented to the chairman of the Muslim Religious Council of Arbiters, Dr. Mashoor Fawaz. During the interview, Dr. Fawaz made the position that according to the Qur'an and Sharia, it is mandatory for the believing person to be kept out of illness and to maintain his health, [9]. This position is supported by the religious literature on Islam and health, as there is a consensus that marriage and children are the source of Allah's blessing and mercy, and the Qur'an explicitly states that a healthy and strong believer is better than a sick and weak believer [6].

During the interview, Dr. Fawaz claimed that even from the Qur'an days and early Caliphates it is known that marriage within the family is a source of morbidity and already Omar Ibn al-Khatab spoke of having to be also married outside the tribe in order to preserve the health of the children [9]. This argument is also supported by other researchers in the field of marriage between relatives in Islam [10].

According to Dr. Fawaz the previous Fatwa (a Muslim law ruling) in the field of hereditary screening, as published in the Palestinian Authority, did not receive sufficient resonance in Israel. It should be noted that on the basis of that Fatwa, the law in the Palestinian Authority requiring hereditary pre-wedding checks before marriage registration, was enacted [3]. However, Dr. Fawaz believes this ruling is not well-known in Israel, and this lack of awareness causes the unresponsiveness of believers to carry out hereditary examinations, although the Qur'an and its interpretations explicitly state that a healthy believer is preferable to Allah. This position is supported by additional literature on health in Islam [11].

In light of this interview and after finding additional sources, Dr. Fawaz [12] considered it appropriate to issue and publish a Fatwa on the hereditary screening no' 1066 [9], whose main content is that of health considerations, the wellbeing of the family and the will of Allah, believers are obliged to perform hereditary screening test even before marriage or before becoming pregnant. While this is not a mandatory condition for marriage or divorce, these examinations should be performed to meet the child health requirements of the Sharia.

\section{Summary}

This article presents a special case in which the findings of a Pilot Screening among clerics led to an increased interest in the high religious authority on the subject. The findings of the screening showed that although there is some awareness among Muslim clerics in Israel, there is no high responsiveness to conducting the genetic screening test. This issue is particularly serious, as studies in the field have emphasized the importance of religion in the health of the Muslim population. Furthermore, the importance of screening examinations has been tested in countries around Israel, and in some of them it has been implemented at the legal level as part of promoting public health in light of religious policy.

Dr. Fawaz's [13] decision to make an unequivocal intervention at a Fatwa level based only on the basis of preliminary research and interview indicates the readiness of Israeli Arabs to implement health policy with the support of the religious authorities. There are two facets to this response. On one hand, it is a welcomed initiative on the backdrop of similar initiatives and historical recommendations. On the other hand, it is a very intense response, so there is room for future research to examine the influence and implementation of this Fatwa in Israel's Arab-Muslim population and the truth only Allah (God) knows.

\section{Acknowledgement}

None.

\section{Conflict of Interest}

Author declare no conflict of interest.

\section{References}

1. Central Bureau of Statistics (CBS) (2018) Israel's Population by Religion and Self-Determination of Religiousness: Selected Data from Company Report No 10

2. Romano Zelicha A and Shochat $\mathrm{T}$ (2011) Use of genetic testing and imaging tests for prenatal diagnosis by pregnant women in Israel. Jerusalem: National Center for Disease Control, Ministry of Health.

3. Cousens NE, Gaff CL, Metcalfe SA, Delatycki MB (2010) Carrier screening for beta-thalassaemia: a review of international practice. Eur J Hum Genet 18(10): 1077-1083.

4. Al Aqeel AI (2007) Genetic counseling un the Muslim world: the challenges. $2^{\text {nd }}$ Pan Arab Human Genetic Conference.

5. Tadmouri GO, Nair P, Obeid T, Al Ali MT, Al Khaja N, et al. (2009) Consanguinity and reproductive health among Arabs. Reprod Health 6(1): 17.

6. Anita AR and Aidalina M (2014) A Review of the Islamic approach in public health practices. International Journal of Public Health and Clinical Sciences 1(2): 1-13.

7. Zlotogora J (2014) Genetics and genomic medicine in Israel. Mol Genet Genomic Med 2(2): 85-94.

8. Godard B, Kate L, Evers Kiebooms G, Ayme S (2003) Population genetic screening programmes: principles, techniques, practices, and policies. Eur J Hum Genet 11(2): S49-S87.

9. Fawaz MA (2020) Fatwa: Hereditary Survey Tests No 1066.

10. Khan FZA and Mazhar SB (2018) Current trends of consanguineous marriages and its association with socio-demographic variables in Pakistan. Int J Reprod Contracept Obstet Gynecol 7(5): 699-1705.

11. Stacey A (2008) Health in Islam. Islam House.

12. Fawaz MA (2019) Personal interview with $S$ Gabaren.

13. Fawaz MA (2019) TV channel interview with S Gabaren. 